\title{
Conforto, proteção social e emprego doméstico (Brasil e Região Fluminense, 1960-2000)
}

\author{
Comfort, social protection and domestic employment \\ (Brazil and Fluminense Region, 1960-2000)
}

\author{
Suely Gomes Costa*
}

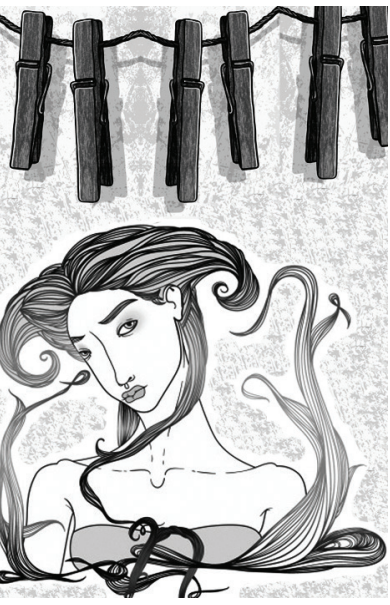

"Se podes olhar, vê. Se podes ver, repara"

(José Saramago.

Epígrafe do livro Ensaio sobre a cegueira).

Resumo: Este texto ocupa-se da história das mulheres, sem perder de vista as relações entre as esferas pública e privada. Examina o trabalho e emprego domésticos no Brasil contemporâneo, tomando-os na sua função precípua: a produção do conforto e da proteção social das casas, uma regularidade de longa duração histórica. Propõe revisões conceituais sobre essa matéria, com base experiências de empregadas domésticas da região metropolitana do Rio de Janeiro, entre os anos 1960 e os dias atuais, bem como de matéria jornalística e televisiva em circulação no tempo presente.

Palavras-chave: História das mulheres. Relações público-privadas. Conforto e proteção social. Maternidade transferida. Demanda em espiral. Trabalho e emprego domésticos.

\begin{abstract}
This article deals with the women's history, without losing sight of the relations between the public and the private spheres. It examines the domestic work and job in contemporary Brazil, and it takes them in their main function: to provide comfort and social protection in the houses, which has been a long term regularity historically speaking. It contains reviews of concepts related to this subject,

* Mestre (1988) e doutora em História (1996). É professora credenciada do Programa de Estudos Pós-Graduados em Política Social e do Programa de Pós-Graduação em História, ambos da UFF, Rio de Janeiro/ RJ, Brasil. Suas pesquisas estão referidas à história das mulheres e às relações de gênero no Brasil contemporâneo.E-mail: suelygomescosta@gmail.com.
\end{abstract}


based on the experiences of domestic maids in the metropolitan region of Rio de Janeiro, from the twentieth century's sixties to the current days, as well as on journalistic and TV reporting from the present time.

Keywords: The women's history. Public-private relations. Comfort and social protection. Moved motherhood. Spiral demand. Domestic work and job.

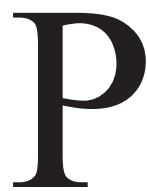
esquisas sobre o mundo doméstico e modos de vida do Rio de Janeiro ao longo do século XIX e matérias em circulação sobre o assunto, entre 2008 e 2012, estimularam-me a acompanhar o debate e a refletir sobre o processo de valorização do emprego doméstico e, por conta disso, de seu presumido declínio, no Brasil dos dias atuais (Costa, 1996). Nessa retomada, animei-me a entrevistar empregadas domésticas com as quais convivi por muitos anos. Foram realizadas por mim entrevistas com Ana Célia N. Souza, em 2009, 2010 e 2011; Maria Arcanjo e Vania Rocha em 2011, segundo regras em vigor. O emprego doméstico e seguidos informes sobre o trabalho doméstico, o infantil e as novas classes médias no Brasil foram selecionadas por mim, entre 2010 e 2012, em periódicos que assino, como $O$ Globo e a Folha de S.Paulo. De interesse do tema, foram também novelas da TV Globo de 2012 (Cheia de charme e Avenida Brasil). Também, foi de muita valia o site: $<\mathrm{http} / / \mathrm{www}$.jornaldedebates.com.br/debate/ quem-classe-media-no-brasil/12420>. ${ }^{1}$

Trabalho e emprego domésticos correspondem a tradições de produção de conforto e de proteção social nas habitações de todos os tempos. Muito antes de ser emprego é trabalho, ou seja, energia humana, sobretudo feminina, essa que formata a economia das casas e que conforma tarefas associadas a essa produção. Já emprego é uma relação estável entre empregador e pessoa empregada, disposta em dispositivos legais. As abordagens econômicas sobre o uso dessa energia nunca associam trabalho e emprego domésticos à criação da riqueza social. Por não produzirem mercadorias, receberá pouca atenção da teoria econômica clássica (Marx, 1975). O trabalho doméstico no Brasil, mesmo quando é emprego, tem um elevado grau de informalidade.

1. Entrevistas com Ana Célia N. Souza em 2009, 2010 e 2011; Maria Arcanjo e Vania Rocha em 2011. O Globo e a Folha de S.Paulo, entre 2010 e 2012, publicaram seguidos informes sobre o trabalho doméstico, o infantil e as novas classes médias no Brasil. De interesse para o tema, foram as novelas da TV Globo (Cheias de charme e Avenida Brasil) em 2012, e a matéria disponível em: <http://www.jornaldedebates.com.br/debate/quem-classe-media-no-brasil/12420. Acesso em: 12 set. 2008>. 


\section{Mil nadas}

Ao governo das casas e das famílias, com e sem trabalhadores domésticos, corresponde a missão precípua de produzir conforto e proteção social das famílias como uma obrigação das mulheres. Na representação de rainhas do lar, por muito tempo, mulheres obrigaram-se ao comando certo de um complexo reino. Em algum momento, pelo mesmo comando, se sentirão depreciadas. A valorização, ou não, do emprego doméstico se inscreve em regras civilizatórias emanadas desse governo; dependerá do bom e do mau cumprimento delas, segundo quem emprega.

Embora produzindo conforto e proteção social, tarefas domésticas tem sido traduzidas como mil nadas, como faz Machado de Assis ao apresentar o periódico O Jornal das Famílias, um "[...] verdadeiro jornal para senhoras, pela escolha do gênero de escritos originais que publica e pelas novidades de modas, música, desenhos, bordados, esses mil nadas, tão necessários ao bom tom" (Assis, 1938). Mil nadas de significados mais precisos estão em duas gravuras do século XVII (Borin, 1997, p. 282-283). Publicadas, uma ao lado da outra, expressam representações de misteres femininos, no caso, comuns ao universo doméstico europeu Numa, a Dona de Casa, de autor desconhecido, à moda de Giuseppe Arcimbold (1527-1593), é a caricata cabeça de mulher feita com utensílios domésticos: carretel, vassoura, balde, louças, ralar, espanador, coador, panos etc. e, mesmo, um gato, um símbolo da domesticidade. $\mathrm{Na}$ base dessa figura, curtos versos rimam ce pauvre visage (esta pobre face) com marriage (casamento) e ménage (serviços domésticos). Nessa associação, a face desgastada parece noticiar a energia consumida por obrigações do casamento e aplicada a fazeres das casas. Esses utensílios cifram códigos de ações repetidas, rituais, ritmos, gestos e esforços de produção do conforto das famílias e de sua proteção social, em muitos usos do tempo feminino. Utensílios domésticos são nomeados, entre nós, como quinquilharias, bugiarias, bugigangas, badulaques, trastes, bagatelas, fancarias, trem, palavras que também guardam o sentido de mil nadas ou coisas sem valor. Noutra, A bela caridade, de Crispin du Pas (1628), um belo rosto feminino tatuado por símbolos e frases referidos à virtude cristã, registra compromissos com a proteção social próxima e societária. Nesses signos estão mensagens que traduzem a missão feminina de guiar o mundo com amor, de lutar por ele, de propagar e defender razões morais da vida em comum. Juntas, as suas gravuras projetam sinais políticos presentes nas mútuas relações entre as esferas privada e pública, essas que orientam o governo das famílias, ainda 
nos dias de hoje. Mil nadas, antes variadas obrigações, expressam deveres de cuidar em nome da virtude cristã.

Da produção de conforto através do trabalho e do emprego doméstico resultariam serviços e afetos, segundo regras fixadas em costumes, tratos privados e relações sociais para as comodidades do dia a dia. Como proteção social primária ou próxima há deveres e obrigações das famílias, de muitas parentelas e de amigos de muito tempo. Essas práticas mudaram e modelos clássicos de famílias, nem sempre ofereceriam a certeza de apoio seguro. Trajetórias pessoais mostram deslocamentos de muitas direções, fazendo e refazendo vínculos instáveis e plurais.

O conforto será adquirido como mercadoria e conhecerá variações conforme a disponibilidade de dinheiro de cada um para comprar utilidades e serviços. Modos de produzir a proteção social primária, essa restrita à família de sangue, cresce de complexidade na medida em que as famílias se fragmentam e encolhem. Instituições destinadas a cuidar de pessoas, sob muitas contingências, também mudaram; tornaram-se lugares de ganhos financeiro e ao alcance de poucos.

Houve um tempo em que o recebimento de algo estimado como de valor monetário devia ser recompensado apenas com presentes e favores. Mas razões morais e sentimentos de dever e de gratidão não estão abolidos desses nossos tempos; eles prosseguem em códigos e práticas de reciprocidade, sob automatismos sociais nem sempre reconhecidos. Inscrevem-se em símbolos que tem recodificado relações de trocas, nem sempre monetárias, mas de muitos sinais civilizadores. Na língua por-

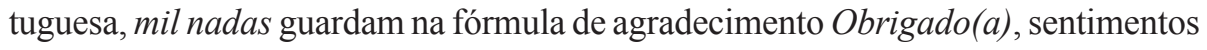
do sujeito devedor de favor. Invariável (e modesta) a resposta a ela — não importa quão árduo tenha sido o favor, é: — De nada! Ou mesmo: — Por nada!

Os tempos são outros, e mesmo indícios de continuidades que aqui e ali se manifestam nem sempre preservam os mesmos sentidos.

\section{Trabalho doméstico e saídas femininas}

Em séculos de regime escravista, o trabalho doméstico no Brasil definirá regras e obrigações de homens e mulheres, adultos e crianças na condição de escravos(as) de dentro, sempre, nas proximidades de seus senhores e no cume da hierarquia escrava. O conceito de Dona que, em Portugal e no Brasil, indicava a posição feminina no quadro da nobreza, sob escravismo, traduz bem o poder de posse das 
pessoas. Esse regime, porém, admite tarefas de escravos(as) de ganho e alugados(as) das quais também decorrem pequenas remunerações. Os alugados(as) subsistirão mesmo após a abolição (Morley, 1997). No decorrer do século XIX, europeus aqui chegados registram seus desconfortos com as relações escravistas (Costa, 1996). Eles irão tensionar ambientes em que circulam e podem ter atuado, de muitas formas, na atenuação dos rigores desse regime de trabalho (Luccock, 1975; Ebel (1972), Graham, 1990; Darwin, 1974). Modos de produzir conforto e proteção social guardam tradições e ritos e inscrevem-se em usos costumeiros. O trabalho doméstico os repete, mas também os muda, em geral, sob o impacto de mudanças tecnológicas e negociações privadas. Mas é costume que famílias mantenham em suas casas pessoas por elas protegidas, desde muito crianças, num longo aprendizado dos ritos domésticos. Elas se tornam "de confiança" e aptas para o comando do mundo doméstico. Oriundas, tantas vezes, de ramos pobres das mesma ou de outras famílias e, mesmo, de relações de compadrio, distinguem-se essas pessoas "criadas" das demais. É usual que sejam empregadas no exercício do comando, do controle e da vigilância, enfim, de todo o serviço da casa. Nem sempre suas responsabilidades são remuneradas; muitas vezes, significam a compensação pelo abrigo e subsistência recebidos ao longo de suas vidas; em troca, há sempre favores e doações. Em todas as regiões do país, esse costume terá continuidades na execução do emprego doméstico por pessoas livres.

Mulheres, sob tradições escravistas, puderam reduzir muitas tarefas de cuidados da prole, essas que, por muito séculos, foram exercidas por amas de leite, amas-secas e babás. A abolição imporá novas regras. Não foi por outra razão que a legislação do emprego doméstico pós-abolição tenta manter formas de controle do trabalho próprias à escravidão (Costa, 1996). Muitas são as tensões das saídas das mulheres para o público (AGCRJ). ${ }^{2}$ Com a abolição da escravatura e com o incremento dos deslocamentos das mulheres para ocupações variadas fora do lar, cresce a exigência de pessoas "de confiança" para cuidados das proles. Isso parece mudar quando encargos domésticos tornam-se emprego, sob remunerações fixadas em negociações privadas. Os valores irão variar, não apenas, conforme tarefas de diferentes complexidades e hierarquias de renda e posição social dos empregadores. Com a crescente saída das mulheres para o espaço público, esses cuidados exigem a continuidade de relações de confiança, pois, significam uma

2. Ver: Serviço Doméstico. Propostas de Antonio Felix Garcia de Infante, Josino Emiliano da Silva, Jeronymo d'Assis Pinto Freitas \& C. 1884. Códice 48-4-56. AGCERJ, p. 46-47. 
outra jornada de trabalho feminino, essa que até então nunca adquirira qualquer expressão econômica.

\section{População não ocupada/desocupada, modos de vida e sobrevivência}

Sob mudanças de muitos tempos e lugares, há uma continuidade: as mulheres que trabalham fora de seus lares empregam energia e tempo na produção do conforto e da proteção social de muitas pessoas, em geral, administrando o tempo de uma jornada dentro e outra fora de suas casas. Isso chega aos nossos dias. Todavia, por mais que assim se ocupem, critérios econômicos nunca consideram esse tempo aplicado as suas casas como de efetivo trabalho. Se nada recebem como remuneração, se não há contrato de trabalho, se não há leis de reconhecimento dele como atividade de sinal econômico, não será jamais considerado.

Nessa situação, essa é a sina da "população economicamente inativa", ou seja, "não classificada como ocupada" ou então, "classificada como desocupada". ${ }^{3}$ Tal critério, por uma dada perspectiva econômica, desconsidera aquele amplo conjunto de tarefas, feito de mil nadas, dedicado a modos de reproduzir a vida. Eles podem ter ou não registros, podem favorecer ganhos ou não, mas se inscrevem sempre como uma experiência societária nessa nossa vida em comum, ocupando e exaurindo, sim, intensamente as mulheres, adultas e crianças, mais que os homens, em ações cotidianas repetitivas e variadas, mas sem nenhum sinal econômico.

Com frequência, entre os séculos XVI e XIX e mesmo XX, nossos modos de vida intrigaram europeus chegados ao Brasil. Sempre maravilhados com a abundância de bens de uso corrente próprios à natureza tropical, incomodavam-se com os ritmos de trabalho que, em geral, eram sentidos como "preguiça". Um registro de nosso tempo refere-se a costumes brasileiros como esses que, "em clima quente, tornavam a vida agradável - não predispunham ao esforço técnico, considerado pouco útil à vida" (Mauro, 1986). Essa percepção não consegue desvendar as singularidades das relações de homens e mulheres do Brasil com a natureza, plena de recursos de subsistência, esses que, ao longo de muitos séculos, os tem cercado. Não apreende que, nos sucessivos avanços de ocupação de novas fronteiras, os brasileiros só conduziam o que podiam carregar, sobrevivendo aos desafios de abrir caminhos

3. Disponível em: <www.ibge.gov.br/home/estatistica/populacao/.../conceitos.shtm>. Acesso em: 20 dez. 2012. 
por entre matas virgens porque lhes bastava retirar delas o necessário, em ritmos próprios a essas muito peculiares relações com a natureza. Predispuseram-se, pois, a modos de vida que dispensaram ou pouco incorporaram esforço técnico, por não lhes ser de qualquer utilidade diante de circunstâncias ambientais que bem conhecem.

A invenção de tradições de vida na floresta permanece em costumes que chegam aos nossos dias, permitindo traduzi-los agora como modos adequados de sobrevivência. Naqueles tempos, para o necessário à vida, bastava recriar e atualizar usos e costumes há muito tempo superados nas áreas produtoras de tecnologias (Costa, 1988). Na Europa, o uso intensivo das áreas florestais esgotará a base técnica assentada na madeira; esse padrão será substituído por outro que, com base no ferro, no carvão de pedra e na energia a vapor, impulsionará a revolução industrial. A experiência de Portugal é emblemática: a extinção de madeiras para consumo interno se inicia no século XII e será mais e mais agravada por demandas de construção naval, uma exigência da expansão marítima do século XV e seguintes. Esta vai impor a necessidade de importar madeiras do norte da Europa e, também, do Brasil, dos Açores, da Madeira e de Goa. Leis régias de proteção de florestas foram anuladas por política de incentivos à construção de navios para o comércio marítimo e a aumentos de receitas do Império português. Já no século XVIII e XIX, as "importações de madeira foram entre 4 a 6.7 vezes superiores às exportações" (Reboredo e Pais, 2012). A marcha em direção às áreas de matas e sua ocupação deixa rastros de destruição. A intensidade da destruição dos recursos naturais no Brasil, desde o século XVI, estará ainda nas formas extensivas de uso da terra para a produção agrária de variados artigos de exportação e de consumo interno e chega aos dias atuais.

Esse padrão vai recriar no espaço domésticos, em várias escalas, a agricultura de floresta, própria à área tropical do planeta (Sahlins, 1970). Peculiar a nativos do Brasil e a povos da África, o plantio intercalar, sua característica principal, associará, com alta produtividade, à cultura de exportação a de subsistência.

As relações dos homens com a natureza mesmo redefinidas, manterão antigas tradições. Reservas de recursos naturais no vasto território brasileiro, ainda em tempos de baixa densidade demográfica e pouca incorporação tecnológica, serão submetidas extensivamente a queimadas, como modo de vencer as densas áreas de matas. Mas fronteiras agrícolas serão ampliadas, mantendo-se em muitas delas esse modo de plantio, ainda hoje praticado com bastante vantagem. Essa tem sido a prática que irá regular modos de viver de uma grande parte das famílias brasileiras. Outras práticas serão produzidas com saberes europeus, indígenas e africanos, como 
as de produção de utensílios de madeira, cerâmica, barro, palha, algodão, ferro etc., dispensando largamente sua importação. O conforto doméstico de várias regiões do país ainda hoje expõem objetos artesanalmente produzidos, em tradições agora valorizadas por seus significados civilizadores. Com muito trabalho, criaram conforto e, mais importante, supriram demandas de segmentos sociais muito pobres, dispensando produtos importados. Esses modos de produzir sem esforço técnico tem ainda outro significado civilizatório: eles se adequarão à escassez de moedas engendrado pelas relações escravistas por quase quatro séculos, concentradas em restritos círculos sociais, um automatismo social de muitas vantagens. Em larga escala, essa reiterada escassez de moeda favorece a autarquia doméstica e, por séculos, tornam invisíveis modos de vida que fazem a prosperidade da chamada economia informal, de tanta presença no país (Costa, 1988). A produção artesanal de produtos necessários à vida é um imperativo da produção do conforto da casa em seu dia a dia. Ela presidirá a transição para o trabalho livre e assalariado, mas não deixa de prosseguir através dos que muito se ocupam com tarefas de subsistência, com baixa ou nenhuma remuneração, e com larga ocupação de mulheres. Essa tendência serve ainda para fixar patamares de remuneração do emprego doméstico nos dias de hoje.

Note-se a regularidade da sempre irrisória remuneração do emprego doméstico. Trabalhos aplicados à subsistência familiar, todavia, atuam na formação dos preços e dos salários. Práticas que recolhem e plantam alimentos para consumo — caso das ervas, frutos, folhas diversas, tubérculos, grãos - de animais caçados e pescados em pequena escala ou criados em quintais, em terrenos baldios, no entorno de casas, até mesmo nas ruas e em praças públicas, compõem um conjunto de tarefas desconsiderado nos cálculos econômicos. Mas esse é um resultado do trabalho de pessoas intensamente ocupadas com a subsistência familiar. A natureza generosa, exaustivamente ilustrada no passado por tantos europeus, alimentou e continua alimentando milhares de homens e mulheres, adultos e crianças de ontem e de hoje, de muitas formas. São ainda obrigações de pessoas que, mesmo hoje, continuam cuidando dessa subsistência familiar, nem mensurada em sua extensão e valor econômicos, nem avaliada na formação de nossos níveis de preços e de salários.

Célia (1965), branca, vinda de São Fidelis (RJ), interior do agrário fluminense, moradora em Itaboraí (RJ), município da região metropolitana do Rio de Janeiro, conta-me que, em seu bairro é comum a troca de uns produtos disponíveis ou plantados por ela e pelo marido no seu terreno, por outros, medidos em equivalências 
costumeiras. Empresta-se um tanto disso por um tanto daquilo, ou seja, uma porção de pó de café por outra de óleo, uma de óleo por um tanto de arroz, mas também alguns maracujás do quintal por uma porção de abóbora recém-colhida, de ovos por um outro produto etc. Trocam-se ainda serviços: erguer uma cumeeira na construção de uma casa, por exemplo, é ter certeza de retribuição de idêntico serviço quando necessário. Tudo isso se faz em presença de uma lauta refeição, também uma comemoração. Dar uma olhadinha numa criança, enquanto a mãe dela trabalha, é tarefa trocada por um ou outro servicinho ou produto. Esses modos de viver e de trocar se desenvolvem numa das maiores regiões metropolitanas dos país. Eles atendem a necessidades de pessoas próximas e protelam gastos no mercado, sempre que sobra mês e falta salário.

Nos anos 1970, meu pai, médico sanitarista, viu-se diretor do posto de saúde na Ilha da Conceição, em Niterói (RJ), um lugar de construção naval na baía de Guanabara desde os primeiros tempos coloniais. Enfrentou, aí, o que chamou de revolução dos porcos. Questões sanitárias o obrigaram a vetar a criação de porcos soltos nas ruas e ele conheceu forte resistência da população local. Nas negociações com representantes de moradores desse bairro, descobriria a relevância dessa prática para a subsistência da região. Acertou-se, então, a obrigatoriedade de pocilgas sob controle sanitário do posto. Domicílios de periferias urbanas e do interior brasileiro hoje replicam práticas como essas: cavalos, bois e vacas, porcos e aves soltas se alimentam em ruas e estradas. Esses animais tem muitos usos: para transporte, consumo, ou mesmo para troca e venda. Ainda que hoje restrita, a disponibilidade de recursos naturais e daqueles advindos de plantio de vários produtos para consumo em pequena escala não tem sido avaliada em seus significados para a subsistência das famílias e na regulação da sempre crônica escassez de moeda. São práticas sociais que tanto conservam modos rústicos de vida social, independentes do mercado, como modos de subsistência, nessa tão singular vida urbana (Costa, 1996). A fantástica inventiva doméstica faz, ainda hoje, o conforto das casas e a proteção das famílias. É modo de enfrentamento dessa secular escassez de moeda e de resolver dificuldades daí advindas, sendo socialmente partilhadas por parcelas significativas da população brasileira, mostram práticas de muitos registros (Morley, 1997). Costumes socorrem e formam redes e também, através do trabalho doméstico, servem para firmar o baixo custo/preço do trabalho de milhares de brasileiros. Diante do entra e sai do mercado de trabalho, essas são soluções certas para inseguros ganhos por salários; elas convivem com outras urbano-industriais que avançam. Talvez, por isso, na história do Brasil, sejam tão poucas as crises por escassez 
de alimentos - salvo aquelas pontuais, por questões climáticas e mesmo por conjunturas inflacionárias.

O processo de concentração de renda no país localiza, de um lado, uma faixa de pessoas no topo, seguida de outra no meio da pirâmide social, um conjunto que chega ao mercado; outras estão bem abaixo delas. A industrialização restringida é bem uma expressão dessa economia que administra sua incapacidade de estender-se a todos os campos da produção e que, assim, filia pouco a pouco trabalhadores ao emprego industrial. Essa experiência cria uma nação dentro de outra. Também impulsiona o trabalho doméstico em direção ao autoabastecimento, associado, tantas vezes, ao trabalho por conta própria. Ignorar tudo isso é um modo certo de tornar invisível essa história. Mesmo nessa hoje alargada economia urbana, grandes contingentes populacionais não tem podido dispensar práticas tradicionais de subsistência, como as indicadas por Célia. Além de servirem para enfrentar oscilações econômicas e baixos salários complementados, regularmente por rendas advindas de variadas atividades informais e ocasionais, elas constituem uma outra forma de expressão de formas de sobrevivência de contingentes humanos que Marx conceituaria como formadores do exército industrial de reserva, sediados nas periferias metropolitanas do país, em berçários de pobreza, convenientemente regulando preços de trabalhos diversos dessas regiões. Por isso, mortes por fome nunca assumiram, no presente e no passado, os níveis verificados em outras partes do mundo, sob a Revolução Industrial, ainda que outros males aí se apresentem.

Quão falso é admitir que homens, mulheres e crianças não empregados sejam assim, uma população economicamente inativa por desocupada! As estatísticas usuais de exame do trabalho e do emprego domésticos merecem ser reexaminadas, diante dessa extensa experiência societária. Essa energia humana, em grande parte feminina, há séculos, cria e recria de graça bens e serviços de manutenção de mais e mais trabalhadores formais e informais. Como trabalho, porém, não adquire valor monetário ou seja, é sempre barato. Seus muitos significados também permanecem invisíveis. Cabe, pois, conceituar e distinguir o trabalho do emprego doméstico, mas lembrando que um, nem sempre, anula o outro.

\section{Saídas das mulheres e maternidade transferida}

Em toda a parte, em todos os tempos e modos de vida, saídas de mulheres para atividades fora do lar produziram uma sensível desordem nas formas usuais 
de produção do conforto e da proteção social primária ou próxima (Castel, 1998). Sob avanços da Revolução Industrial e precárias instituições de proteção às crianças, essas saídas têm sido feitas com rompimentos de dado padrão reprodutivo. Elas irão ampliar, sem dúvida, riscos de vida e de saúde sofridos por crianças deixadas em suas casas sem cuidados ou sob cuidados precários, numa época de escassos serviços assistenciais. Isso lembra um documento médico, na Inglaterra examinado por Marx (1975, p. 453-456) onde faz observações preciosa s esse respeito: "Conforme demonstrou uma investigação médica oficial em 1861, pondo-se de lado circunstâncias locais, as altas taxas de mortalidade [de crianças] decorrem principalmente de trabalharem as mães fora de casa". E conclui: "Daí resulta serem as crianças abandonadas e maltratadas". Então, avalia: "Este desleixo se revela na alimentação inadequada ou insuficiente ou no emprego de narcóticos; além disso, as mães desnaturadamente se tornam estranhas a seus próprios filhos, e intencionalmente os deixam morrer de fome ou os envenenam".

No Brasil de ontem e de hoje, também muitas crianças tem conhecido muitos desses riscos; poucos estudos tratam disso (Pinto, 2007). Entretanto, preocupações de cunho maternalista estão em jornais femininos do século XIX, inclusive em matérias propagadas por mulheres abolicionistas em defesa de meninas de rua, filhas de escravas, expondo outros movimentos (Bernardes, 1989). Ações femininas de proteção às crianças na área de saúde, por exemplo, irão juntar mães, mulheres e médicos em muitas ações protecionistas durante a Primeira República e, também serão expressas por mulheres da primeira onda feminista (Freyre, 2009; Soihet, 2006). Em conjunto, fazem a defesa de políticas de assistência à mulher e à criança, quando são crescentes as saídas das mulheres de todas as camadas sociais para o espaço público, no cumprimento de algumas tarefas longe do lar; essas saídas ampliam demandas por emprego doméstico. Acionadas por essas saídas femininas, crescem as tensões e novas regras de viver e sobreviver mudam antigos modos de governar as famílias.

No início do século XX, dispositivos legais sobre o emprego doméstico, entendido como a relação remunerada entre um(a) empregado(a) e um(a) empregador(a), não vão além de tentativas de manutenção do controle disciplinar do extinto trabalho escravo (Costa, 1996). O emergente movimento de empregadas domésticas dos anos 1920 será feito por mulheres negras associadas ao Partido Comunista Brasileiro (PCB), que denuncia as condições precárias do exercício desse emprego, vinculando-as ao legado da escravidão doméstica (Bernardino-Costa, 2007). Embora essa organização sindical se mantenha, o reconhecimento 
desse trabalho como emprego não será inscrito nas leis trabalhistas dos anos 1940. As saídas de mulheres das camadas sociais médias e médias altas, porém, não deixarão de se intensificar nas conjunturas seguintes. Nos anos 1970, sob o milagre brasileiro, elas ampliarão como nunca a demanda por emprego doméstico, indica Saffioti e, com base em Langoni, registra o surgimento das novas classes médias de então, como hoje, suas empregadoras (Saffiotti, 1978; Langoni, 1973). Não é por outra razão que a legislação que primeiro regula o trabalho doméstico é de 1972; embora seja um avanço, não consolida plenamente direitos trabalhistas. Só no ano de 2013, um projeto de lei foi posto em discussão concedendo ao emprego doméstico todas as prerrogativas trabalhistas. ${ }^{4}$ Aprovada a lei, falta-lhe, nos dias atuais, a necessária regulamentação.

A profissionalização das mulheres se estende a todas as camadas sociais e mesmo em direção a profissões tradicionalmente masculinas. Isso que é um ganho político, serve também para reduzir os custos médios da mão de obra empregada. Para as mesmas atividades, salários femininos são sempre muito inferiores aos dos homens, além de não alterar a maternidade transferida de umas para outras mulheres, mantendo a tradicional interdependência de mulheres entre si. Cuidados das famílias são prestados por empregadas de confiança, sob supervisão de pessoas de uma mesma família, ou de famílias próximas, por mulheres de diferentes e das mesmas camadas sociais, podendo, ocorrer, conforme o caso, sem qualquer remuneração, mas com troca de favores. É usual que pessoas menos favorecidas do mesmo círculo familiar cooperem com os seus membros e, por muitos tratos, recebam por isso alguma forma de remuneração. Conta-se ainda com as relações de compadrio. Incorporam-se a esse trabalho, ainda pessoas criadas por famílias, sob circunstâncias as mais diversas, um antigo costume de muitas tradições. A intensidade de energia aplicada aos cuidados da casa, de crianças, de doentes e de idosos varia; esse costume fixa códigos de deveres e de reciprocidades de pessoas próximas. Todavia, embora seja trabalho doméstico, a informalidade dessas relações próximas não deixa registros.

Faltam-nos estudos de modos de vida; eles têm dado rumos ao modelo de proteção social brasileira que chega aos nossos dias. Ao longo da história brasileira, costumes domésticos, têm dispensado estruturas de cuidados, essas da proteção social, de iniciativa pública e mesmo privada, daí seus outros sinais econômicos.

4. Disponível em: <http://www.mte.gov.br/trab_domestico/trab_domestico_direitos.asp $>$. Acesso em: 20 dez. 2012. 
Eles vêm permitindo, por séculos, economizar investimentos públicos em creches, cancelar ou adiar o projeto de escolas públicas em tempo integral de larga cobertura e, mesmo, regular a oferta de abrigo para pessoas doentes e idosas. Até alguns anos do século XX, doenças como a tuberculose, antes da descoberta de sua cura, eram cuidadas em casa, reservando-se até ambientes de isolamento. Farmácias caseiras são exemplos dessa febril atividade feminina de produzir cuidados. E isso permanece: nos séculos XX e XXI, estão aí, sob a recente reforma psiquiátrica; essa mesma tradição vem devolvendo às casas os cuidados de doentes mentais (Passos, 2010). Sob privatização crescente dos serviços de saúde mental, essa transferência de cuidados de doentes psiquiátricos pobres para as suas famílias recriam serviços executados e não pagos na esfera privada, multiplicando responsabilidades, sempre apoiados nos sagrados deveres da maternidade, com larga redução de custos para serviços públicos. No home care, tratos de doentes transferidos a membros das famílias são sempre uma certeza de ganhos das corporações médicas.

\section{Valorização e declínio do trabalho doméstico}

Afirma-se, com frequência, que hoje, a valorização do emprego doméstico está trazendo, como consequência, seu declínio. Tudo isso e o projeto de estender-lhe plenos direitos trabalhistas estaria alçando-o a patamares do Primeiro Mundo. Insiste-se como nos anos 1970, em associar a valorização desse emprego ao modelo de crescimento econômico, ao surgimento de novos empregos e, mesmo, à expansão dos segmentos médios no Brasil, como hoje a da chamada classe média C. Salários atraentes pagos por famílias de alta renda por serviços de babás, cozinheiras, lavadeiras, faxineiras, cuidadoras em geral, ganham destaque em periódicos. Com esse sentido, a matéria publicada num periódico sobre o caso de Deka e outras empregadas domésticas é exemplar (Regar, 2011).

Brasileira, parda, de 29 anos, casada, moradora de São Gonçalo (RJ), Deka é tomada como emblema dessa presumida valorização Regar, 2011). Proprietária de uma casa de $140 \mathrm{~m}^{2}$ em construção em São Gonçalo (RJ), com curso médio completo e o técnico de enfermagem, ela fala inglês, morou na Austrália, usa computador, dirige automóvel e tem um cartão de crédito para compras da família que a emprega. Tem folga nos fins de semana, recebendo $\mathrm{R} \$ 1.700,00$ por mês para um conjunto de tarefas, misto de secretária, motorista, enfermeira e cuidadora de duas 
crianças. O uso de automóvel para seus deslocamentos sugere, porém, uma solução para a intensidade de suas tarefas e as necessidades de economias de tempo. O automóvel, no caso, serve à rapidez dos deslocamentos necessários e isso favorece ao cumprimento de dada pauta de tarefas. Sua empregadora é uma juíza. Essas condições são bastante incomuns para o conjunto das experiências das empregadas domésticas do país, bastando considerar que o nível salarial da empregadora e o da empregada correspondem a uma fração mínima das faixas de renda paga às mulheres, ainda mais daquelas contidas na pirâmide salarial dos servidores públicos da nação. A oferta de salários, antes e agora, acima da média usual para o emprego doméstico, tem sido dada por essa sempre muito estreita faixa superior da pirâmide de renda do país, portanto, uma exclusividade de alguns poucos(as) empregadores(as) e empregadas. A experiência de Deka, por enquanto, generaliza uma exceção. É de se perguntar ainda por que ela não encontrou colocação nem salário correspondentes a suas várias habilitações?

Essa experiência nada tem de nova. Antes e ao longo dos nossos séculos de história e mesmo hoje, no Brasil, famílias de rendas altas nunca deixaram de contratar cuidadoras de crianças e de jovens, vindas da Europa, todas letradas e preparadas para essa função por salários elevados, mesmo sob o regime escravista; até desfrutavam de serviços de escravas de dentro ou de serviços de empregadas de confiança das famílias, mostram muitos registros.

Com base na experiência de Deka, afirma-se ainda a tendência ao declínio do emprego doméstico. Na atual conjuntura, a recente experiência norte-americana aponta um outro fenômeno: lá, o declínio do emprego doméstico vincula-se ao amplo desemprego atual das camadas de rendas médias altas e médias e à necessária redução de gastos próprios a seus usuais padrões de vida (Huffington, 2011). Há mais questões a considerar. No Brasil, segmentos sociais médios de diferentes níveis de renda, mesmo os que se declaram pobres, pagam por esse trabalho valores de muitas variações para atividades também muito diversas. ${ }^{5}$ Não leva em conta, porém, que essa variação faz confundir alhos com bugalhos.

Essa valorização não desencadeia, necessariamente, o declínio do conjunto do emprego doméstico no país. Esse emprego se valoriza na medida em que mais mulheres se deslocam para diversas atividades remuneradas no mercado, ou seja, fora de suas casas, sem contar com estruturas de cuidados ou por tê-las a preços

5. Disponível em: <http://www.jornaldedebates.com.br/debate/quem-classe-media-no-brasil/12420>. Acesso em: 12 set. 2008. 
muito elevados. O emprego doméstico se move, se segmenta e se regra por mercados formados por empregadores de vários níveis de renda e graus diversos de expectativas quanto a serviços e jornadas a pagar. É composto por tarefas muito diferentes e suas remunerações têm muitas variações. Esse trabalho se valoriza tendencialmente já nos anos 1960 do século passado; ela não é só conjuntural. A presumida pressão exercida pelo caso de Deka sobre o mercado é restrita: remunerações elevadas do emprego doméstico estão ocorrendo hoje, como no passado, no estreito círculo de algumas famílias brasileiras, de pouco impacto sobre o conjunto desse mesmo emprego nas demais camadas sociais, de rendas muito variadas.

As saídas das mulheres de diferentes segmentos sociais para o espaço público não cessam de crescer, desde os anos 1960. O emprego doméstico se redefine ainda no interior de conquistas de direitos reprodutivos, bem como de acessos a padrões tecnológicos desigualmente alcançados. Nos anos 1960, além do processo de urbanização que valoriza o emprego feminino, em geral e o doméstico, em particular, as mulheres viam-se impedidas de acessos a certos empregos por se ocuparem muito tempo com suas proles e sucessivas gravidezes. Já mulheres das camadas médias e altas reduzem, suas taxas de fecundidade, desde então, sob sucessivas quedas: elas haviam obtido acessos a contraceptivos disponíveis no mercado. Além disso, através de decisões próprias e de acordo com seus médicos, puderam pagar pelo parto cirúrgico e, através de cesariana, obtiveram a desejada laqueadura de trompas, forma de esterilização radical, adotada em larga escala. Essa opção não cessará mais de crescer. Sob muitas lutas, o acesso aos anticoncepcionais será assegurado pelo setor público a mulheres de menor renda, mas o direito à esterilização de homens e mulheres pobres, só será reconhecido nos anos 1990 e, mesmo hoje, mantém-se bastante restrito. Até pouco tempo, a fertilidade das mulheres pobres era maior que a das camadas sociais médias e altas; a inversão dessa tendência só mudou há pouco tempo. Também as taxas de mortalidade por aborto incidem sobre as mulheres pobres, permanecendo ainda hoje elevadas. E isso sim repercutirá na oferta futura desse trabalho.

\section{Demanda em espiral}

As saídas femininas exigem estruturas públicas e privadas de proteção social. A ausência delas favorece a formação de uma demanda em espiral por trabalho 
doméstico, conformada por atividades muito variadas. Com essas saídas, restaura-se o processo de maternidade transferida de umas mulheres para outras, tão presente ainda nos dias atuais. E tudo isso tem significados econômicos ocultos. Há indicações de que esse trabalho não deixa de se valorizar, mesmo sob essas circunstâncias. Nos dias atuais, cada mulher que sai de casa para um emprego, transfere para outras pessoas, adultas e crianças, de ambos os sexos, da própria família ou de fora dela, encargos domésticos. Esse emprego doméstico, conforme as circunstâncias, será formal e informal; este último permanece em áreas de sombra dessa mesma história, por ser regida por tratos nunca registrados. Entretanto, ele é regularmente contratado por mulheres de diferentes segmentos sociais e rendas; as diaristas incluem-se nesse caso. Mesmo mulheres pobres, em acertos singulares, podem dispor desse trabalho. Cada saída de mulheres para cuidados de uma casa significa, no todo ou em parte, uma reafirmação de responsabilidades assentadas em representações de cuidados dados como próprios às mulheres e ao exercício da maternidade. Sob essa experiência, nessa demanda em espiral, o trabalho doméstico infantil ganha sensível expressão e deve ser avaliado. Pelo menos por dois séculos, é essa demanda assim atendida que tem atenuado e superado dificuldades de atenção a crianças, postas por precário número de creches e pelo regime parcial do ensino público; os horários das escolas para crianças e jovens nunca são coincidentes com o das jornadas de trabalho de suas mães; outra é a precariedade de mais serviços para o trato de idosos e de doentes. É óbvio que nada disso atinge mulheres de camadas de médias altas e de altas rendas, que, já nos anos 1970, ao contrário, vão contar com as melhores creches e instituições de ensino em tempo integral para cuidados de seus filhos, com abrigos e hospitais especializados para seus velhos e doentes, todos caros e pagos. A lenta incorporação de tecnologia pelas casas de menor renda também realimenta a rusticidade de modos de vida que exige um tempo maior de trabalho aplicado à própria casa.

\section{Diversidade de tratos domésticos}

Já no começo dos anos 1970, acentua-se a tendência de as trabalhadoras domésticas executarem diferentes trabalhos, em diversas jornadas e em casas de diferentes patroas, algumas mesmo em tempos parciais de um mesmo dia, obtendo sempre, sob a forma de diárias por tarefas, obtendo daí rendas mais elevadas, conforme a freguesia. 
Três empregadas domésticas, em diferentes experiências, narram suas trajetórias. Maria (1938-2011), veio de Cantagalo (RJ) para a cidade do Rio de Janeiro, nos anos 1960, onde empregou-se. Depois, casada, seguiu para Niterói, onde irá morar e trabalhar. Célia (1965-) saiu de São Fidelis (RJ), veio primeiro, para São Gonçalo e depois empregou-se em Niterói, cidades desse mesmo estado. Vânia (1950) saiu de Itaperuna (RJ), para Niterói, foi empregada doméstica, sucessivamente, de duas casas por muito tempo, ambas de mesmo nível de renda; numa, passava fome, trabalhava e ganhava pouco; noutra ganhará mais com mais trabalho, porém, contando com ajuda de outras duas empregadas, pagas por tarefa. Saiu para ser auxiliar de dentista e, logo depois casou-se, retornando à Itaperuna, sua cidade natal, onde mora e não mais trabalha. Todas se deslocaram de cidades de regiões agrárias em declínio para a região metropolitana do Rio de Janeiro, com seus muitos berçários de pobreza: Maria, entre anos 1960 e 2011, Vânia, de meados dos anos 1960 a fins dos anos 1980 e Célia, entre 1990 e os dias que correm.

Maria, negra, entre meados e fins dos anos 1960, será lavadeira de muitas casas. Seu marido, era pintor de paredes. Foi moradora de uma favela no Caramujo, em Niterói. No início dos anos 1970, por seus trabalhos de lavadeira e passadeira para famílias de segmentos de pequenas rendas, recebia pagamento por trouxa de roupas lavada em sua própria casa, com água que tinha que carregar e sabão que fornecia; ganhava pouco por tarefas muito pesadas. Mas esse era um modo de conciliar cuidados de seus dois filhos, uma menina e um menino, ainda pequenos. Recorria, de quando em vez, à família do marido, moradora das proximidades de sua casa, sem qualquer remuneração. Entre meados e fins dos anos 1960, será, pela primeira vez, lavadeira diarista de dentro de uma residência. Através dessa família, de maior renda e status social, amplia contatos com pessoas de camadas sociais mais altas, e será empregada de muitas delas para a feitura de serviços vários e remunerações mais generosas. Maria faz-se substituir, aos poucos, por outras empregadas, no atendimento de sua antiga freguesia, na medida em que firma novos contratos. De lavadeira e passadeira de todas as roupas passa a faxineira com jornada definida. Em algumas casas, limita-se a uma ou mais tarefas restritas, numa única jornada de meio tempo, ora para lustrar metais, ora como lavadeira e passadeira de panos delicados quando se beneficia do uso de produtos químicos, da máquina de lavar, do ferro elétrico, por muito tempo, utilidades fora de seu alcance de uso em sua casa. Descobriu que, para horas pagas por tarefas reduzidas, não convinha ser cozinheira, nem cuidadora de crianças. Mais tarde, ocupará um apartamento de sua propriedade no bairro do Coelho, em São Gonçalo, também na região metropolitana do Rio 
de Janeiro. Nunca deixou de ter mercado certo para suas cocadas, balas de coco, doces e bolos feitos em sua casa, em noites adentro e nos fins de semana, ora como encomenda, ora como presentes. Vania, como muitas mulheres desses tempos, morou em cubículos, em meio a amontoados de despejos, nos apartamentos de seus patrões. Entretanto, ela e muitas outras souberam estabelecer limites para suas jornadas de trabalho, usufruir períodos de férias, de descanso dominical e, mesmo, gozo de feriados, como Natal e Ano-Novo. Muitas de suas amigas, conta-me, não mais dormirão nos empregos e, ainda, conseguirão cobertura de gastos com transportes. Todas aprenderam a neutralizar a força de "presentinhos" e favores, para assegurar conquistas e seus usos de liberdade.

No início dos anos 1990, Célia, antes de vir para a região metropolitana do Rio de Janeiro, e outras mulheres de São Fidélis, interior do estado, faziam bordados de ponto de cruz e crochê, vendidos por uma moça vinda de Copacabana. Mas os preços dessas peças baixaram aos níveis daqueles pagos por trabalhos idênticos, feitos por mulheres nordestinas, chegados aos montes ao Sudeste. Desde então, não valia mais fazê-los. Célia diz-se orgulhosa por ter tido seus bordados e crochês comprados por dona Lili Marinho, e uma toalha de mesa por uma igreja presbiteriana. Em São Gonçalo inicia uma nova vida: mora com a irmã, será balconista de uma farmácia, sem qualquer registro. Ganhando mal, despede-se. Inicia ainda em São Gonçalo sua carreira de doméstica, mas além de ganhar pouco, era paga irregularmente e não se sentia bem tratada. Vai trabalhar então na casa de uma família de classe média alta, onde será mais bem remunerada para todo serviço, numa grande casa de condomínio na região oceânica em Niterói, onde conhece Maria. Seus patrões trabalhavam até a noite, sua jornada era extensa e incluía os cuidados da filha pequena do casal. Era usual servir o jantar às 22 horas. Depois de quatro anos, Célia engravida e continua trabalhando até o fim da gestação; desfaz a relação. Sai do emprego. Retorna a São Fidelis, deixa a filha recém-nascida com sua mãe e se emprega no lugar de Maria, que está se aposentando, mantendo só um vínculo empregatício com um salário maior. Em fins dos anos 1990, como tantas mulheres, Célia casa-se com um pequeno funcionário do Estado. Sua filha, já crescida, vem morar com ela e a ajuda, com o padrasto, a cuidar da casa, na sua ausência. Quando pode, faz um dinheirinho a mais com crochê e bordados de ponto de cruz. Célia sempre fez uso de métodos contraceptivos, mesmo assim, engravidou de novo. Com mais de 40 de idade, vive, a seguir, um aborto espontâneo. Decidiu, então, que lhe bastava a filha, pois seu marido já era pai de três filhos de relações anteriores. Maria, casada com um mesmo companheiro por toda a vida, teve apenas um menino e uma menina. Uma gravidez 
tubária, que quase a mataria, limitou-lhe a prole, reduziu seus encargos e ampliou sua autonomia. Vania não teve filhos: casou-se tarde com um viúvo e escolheu ser mãe de seus enteados. Maria, como diarista, obterá rendimentos mais altos que a média salarial desse emprego no país, em transações pessoa a pessoa, todas longe de lutas sindicais. Permanecerá, logo que aposentada num único emprego onde cuidará, ao fim da vida, apenas de roupas de cama e mesa de linho, de roupas finas e caras, limpeza metais preciosos e delicados, em tempos curtos aplicados a tarefas únicas, todas muito bem pagas. Sua presença como diaconisa de uma igreja pentecostal, abriu-lhe muitas oportunidades e prestígio. Seu filho cursou a Universidade Federal Fluminense (UFF) onde fez seu mestrado. Casou-se com uma pessoa formada em pedagogia, também da UFF e sua filha está concluindo o curso de Matemática, nessa mesma universidade. A família de seu filho mora num apartamento do mesmo prédio de Maria. A filha de Maria terminou o segundo grau. Dedicou-se por uns tempos à moda; hoje, trabalha numa empresa promotora de shows de música gospel. Ao morrer, aos 73 anos, sua única filha, solteira, dividia com ela os cuidados da casa. Em 2010, ela dispunha de uma renda em torno de três mil reais, incluídos alguns biscates culinários, informa-me sua nora. Maria, como beneficiária de pensão do marido, dispensou por uns tempos os recolhimentos para a previdência, retendo-os como renda. Terá direito à aposentadoria quando uma de suas patroas, bem aquinhoada de recursos, decide integralizar suas contribuições previdenciárias, concedendo-lhe, ainda, a entrada para a compra do apartamento no Coelho, bairro de São Gonçalo (RJ) e a saída tão desejada da favela no Caramujo em Niterói. Experiências como essas merecem cuidadoso exame, pois, o emprego doméstico arranja-se em muitos tratos. Elas formam, num mesmo conjunto, demandas em espiral dos segmentos de classes de rendas variadas, por emprego doméstico. São demandas desencadeadas por mulheres de rendas diversas, maiores e menores. Mas essa forma de demanda se amplia assentada em redes sociais e em múltiplas formas de comunicação estabelecidas entre mulheres muito plurais.

Também a fórmula para todo o serviço vem caindo em desuso, mostram essas experiências. As negociações e as hierarquias salariais para diferentes trabalhos domésticos, hoje, são muitas variadas; disso pouco se conhece. As mulheres além de demarcar, aprenderam a valorizar suas tarefas. O dono do hotel que me hospedava, em Porto Seguro (BA), de meados dos anos 1980, solicitou-me o favor de não inflar os preços da lavação de roupa a cargo de uma lavadeira, sua vizinha. Corei de vergonha diante dessa advertência e, mais ainda, dos mínimos valores que ele fixava para as trouxas. A lavadeira, atenta, depois de uma sondagem e uma 
estimulante conversa, recebeu de mim preços cariocas por seu trabalho e a certeza do meu silêncio seguida da compra que fiz de seus doces cristalizados.

Em 1972, direitos trabalhistas foram alcançados, mesmo que ainda fossem frouxas as garantias de acesso a eles. Os salários tenderam a crescer na demanda regular por emprego doméstico dessa conjuntura. Também produziram mudanças: abriram-se caminhos coletivos de negociação e lutas: nesses anos, conquistas salariais expressivas vão surgir com diaristas, como Maria, pagas por tarefas e jornadas fixas, ainda que acordadas em tratos privados. Todas elas se moveram, sempre através de redes de amigos(as) e conhecidos(as). Vania, deixou de ser doméstica, logo que se transferiu, ainda em Niterói, para o emprego de auxiliar de dentista em Niterói, irmão de sua última patroa, mantendo vínculos previdenciários. Dividirá um apartamento em Icaraí, bairro nobre de Niterói, com um grupo de amigas, todas elas ex-empregadas domésticas. Casa-se com um viúvo com filhos, funcionário de uma empresa de energia elétrica. Aposenta-se e retorna para Itaperuna, onde continua vivendo. Célia continua no mesmo emprego, há 15 anos, como mensalista, mas trabalha três vezes por semana com jornada de 8 horas, ganha dois salários mínimos, tem carteira assinada e direitos trabalhistas assegurados, menos a cobertura não obrigatória do FGTS. Faz alguns trabalhos de agulha, para ela, momentos de distração. A filha, agora adolescente, inicia o segundo grau em 2013, em uma escola pública; pretende ser veterinária. Maria, com as redes que integrou, mudou seus rumos. As três, em algum momento, contaram com redes e mais pessoas para substituí-las em tarefas de suas casas. Reconheceram a tendência da demanda em espiral. E me informaram que essa demanda chega ao trabalho infantil de muitas formas; elas a viveram.

Significados civilizadores do emprego doméstico, pois, estão dados num quadro social bem mais complexo. Tributário de modos de vida escravista de muitos séculos, o emprego doméstico conserva e, ao mesmo tempo, supera esse legado. Nos dias de hoje, porém, a confirmação desse legado está no registro de que, no total da população ocupada de pretos ou pardos, $62 \%$ estão no trabalho doméstico do conjunto das sete maiores regiões metropolitanas do país (Recife, Salvador, Belo Horizonte, Rio de Janeiro, São Paulo e Porto Alegre), sendo que as três primeiras têm as maiores marcas. Esse mercado atrai mulheres, como Deka, cujas habilitações culturais e técnicas as colocam em níveis salariais que podem ser até inferiores aos que estão recebendo como empregada doméstica. ${ }^{6}$ Em conjunto, indicações usuais de declínio e de valorização do emprego doméstico desconsideram tendências e

6. Ver: Brasil, IBGE, fev. 2010. 
contingências de crescimento do país, construídos na longa duração histórica. Conceitos econômicos tradicionais não oferecem meios de avaliar o tamanho e as variações do trabalho doméstico. Executado sem registros contratuais, é exercido por parcelas consideráveis da população, tida como não ocupada. Conceito como esse desloca um grande conjunto de pessoas para uma área de invisibilidade, essa fora do mercado. De classes, sexos, cores e idades variadas, essas pessoas trabalham sob diferentes formas de contrato - que não as oficiais, como é o caso das diaristas, essas que também compõem a demanda em espiral a ser conhecida. Há, pois, situações históricas por avaliar, nessa presumida tendência de valorização e de declínio do emprego doméstico. Dados esparsos obtidos, em pesquisas qualitativas, expõem indícios que aconselham o exame de tendências do emprego doméstico, com base em novos parâmetros.

Desde os anos 1970, o Brasil conhece uma intensa urbanização e níveis de incorporação técnica em ascensão, intensificando a ocupação de todas as regiões do país, mudando tradicionais quadros de densidade demográfica e sugerindo o surgimento de novas classes médias, como hoje. A expansão econômica dessa conjuntura alargou fluxos migratórios regionais e intrarregionais, dando nitidez a essa demanda em espiral de emprego doméstico feminino e variado em todo o país. Não é por outra razão que, nos anos 1970, trabalhadores rurais e domésticos serão cobertos pela legislação trabalhista, ainda que não plenamente.

As três mulheres entrevistadas começaram a trabalhar, em suas regiões de origem, desde a mais tenra idade. O trabalho infantil é parte nessa mesma demanda em espiral. São tarefas a que se atribuem objetivos de ajudas ou educativos de muitas singularidades. Ensinam-nas a executá-las sob um sempre presente aparato de vigilância. Se mal realizadas, tarefas domésticas trazem transtornos, constrangimentos e, mesmo pesadas punições cotidianas; Cora Coralina, numa estória de Goiás, na virada ao século XIX para o XX, dentre as narrativas de sua avó, seleciona aquela sobre Jesuína, menina de 10 anos, afilhada de patroa de mesmo nome e a seu serviço, com seus encargos, sofrimentos e morte (Coralina, 2001, p. 75-77; Costa, 2008, p. 47-77). Pelo sim e pelo não, a administração de deveres e obrigações em códigos de vigilância e julgamento de ações, de avaliação de razões morais e de correção se desdobram em práticas de segurança e de justiça e na esfera privada em muitas experiências por conhecer. No governo das casas, o trabalho doméstico infantil, como o de Jesuína, é um vasto capítulo dessa tragédia imersa em sombras; de graça, ele ensina, mas também barateia ainda mais o conjunto de tarefas análogas de adultos e instituições. Ao longo do século XX, leis, regulamento e serviços 
de proteção às crianças definiram como razão moral do trabalho infantojuvenil a de torná-las boas cidadãs. O trabalho infantil chega a nossos dias, até mesmo sob o signo da escravidão; suas regras continuam também nos reformatórios contemporâneos. A extensão e a intensidade de obrigações assumidas por crianças de ambos os sexos, desde muito cedo, estão nos casos de Maria, de Célia e de Vania. Eles mostram que o trabalho doméstico infantil apoia/complementa o dos adultos; se há, a remuneração obtida compõe a renda familiar, em geral aplicada ao consumo das próprias crianças. O governo das famílias tem regrado de muitas formas o trabalho infantil, esse feito de mil nadas, seja por conta de uma presumida função disciplinar da criança, seja da expectativa de uma contribuição à sobrevivência de suas famílias. É frequente que instituições de proteção à criança, de caráter público ou privado, tenham ainda hoje esse modelo disciplinar como referência.

\section{Trabalho doméstico, tecnologia e rumos civilizadores}

Na virada do século XIX para o XX, a vida cotidiana consumia muito mais energia (e tempo) em tarefas domésticas que a de hoje. Desde cedo as mulheres de todas as épocas, descobrem e transmitem modos de simplificar tarefas e de restringir obrigações para ganhos de tempo livre. Modos de fazer reprogramam frações de tempo e reduzem esforços físicos e, assim, dão lugar a tempos para outros projetos de vida; receitas do século XIX expressam isso muito bem. Invenções assinalam a busca de economias de tempo, caso de um berço que embala sozinho, registrado na Inventiva brasileira 1870-1910, uma exposição realizada pelo BNDES, na cidade do Rio de Janeiro, em 1994. No passado não muito distante, árduas e pesadas tarefas, tantas feitas à mão, repetiam-se com regularidade diária. Elas prosseguem ainda em muitos lugares do Brasil e do mundo.

A incorporação crescente de novidades substitutas de árduas práticas domésticas, no todo ou em partes de suas etapas, é um outro vasto capítulo dos rumos civilizadores deste nosso país. Ganhos de tempo com o trabalho doméstico continuam associados ao progresso técnico e a seus impactos sobre um dado ambiente social. O recente incentivo dado pelo governo ao crédito voltado para a aquisição de produtos da chamada linha branca (fogão, geladeira, freezer, lavadora, secadora etc.) assenta-se não só no reconhecimento da relevância desses produtos para a liberação do corpo feminino de árduas tarefas, mas também para reprogramar o tempo feminino aplicado ao mundo da casa. Cabe um alerta para o engano que 
associa o acesso à tecnologia ao conforto doméstico, como lembram os estudiosos da habitação (Rybczynski, 1989): "o conforto doméstico definitivamente é um conceito que nada tem a ver com a tecnologia ou, pelo menos, trata-se de um conceito em que a tecnologia foi de uma importância nitidamente secundária”. O emprego de tecnologia na casa pode servir a vários misteres e, de fato, depende de decisões femininas, pois "as mulheres compreendem, mais que os homens, o que é um ambiente doméstico confortável”, diz essa mesma reflexão. Mulheres regulam, em grande parte, o consumo de bens que entram nas casas, por razões as mais variadas, inclusive, por saberem sopesar suas utilidades para usá-los, doá-los ou até mesmo abandoná-los. Nas casas, artigos industriais eliminam etapas de tarefas e as simplificam; não faltam exemplos disso. Mas grandes teses têm generalizado os benefícios do progresso, sem distinguir as circunstâncias que movem as muitas vidas domésticas.

Pessoas de médias, médias altas e altas rendas são as que podem organizar suas vidas segundo práticas articuladas a um mesmo patamar tecnológico. Como empregadoras de mulheres na condição de domésticas, elas geram benefícios pelo uso desses produtos que minimizam o gasto da energia humana aplicada à produção do conforto. Mas, no conjunto, tarefas domésticas que incorporam tecnologias são também responsáveis pela crescente intensificação do trabalho. Assim, economias de tempo produzidas por esses artigos, podem ampliar o rol de atividades a cumprir num mesmo tempo. Além disso, trata-se de uma experiência indicativa de que a articulação de padrões tecnológicos de uma mesma geração depende de renda e isso, mesmo no Brasil de hoje, é restrito a poucos segmentos sociais. Assim, o conforto atribuído genericamente ao consumo de bens de um dado patamar do progresso técnico e à vida urbana, em si, cria ilusões políticas, quando oculta desigualdades sociais presentes no meio social. Vida urbana, em tese, traz economias de tempo, mas isso se seus habitantes dispuserem de bens de uso coletivo e de renda. Empregados(as) domésticos(as) são pessoas pobres; formam o contingente que está na base da pirâmide da desigual distribuição de renda do país. Moram nas periferias dos centros urbanos, lugares sem bens de usos coletivos (água, esgoto. arruamentos, luz, coleta de lixo, transportes de massa confortáveis etc.), tudo que está disponível em bairros de camadas sociais privilegiadas. Essas se distinguem das demais quando na fuga dos desconfortos desses transportes, trafegam em automóveis, vivendo e produzindo o desconforto dos engarrafamentos de cidades construídas segundo desígnios imobiliários. Aos mais pobres tem restado tomar ônibus ao raiar do dia, ainda no escuro, como faz Célia, para evitar os desconfortos 
de condução lotada depois das 7 horas da manhã, o que significa não disponibilidade de transportes de massa de qualidade, mas também o cumprimento de uma jornada de trabalho mais longa, nunca computada como horas de trabalho. A tecnologia doméstica de fato muda ritmos de trabalho. É usual que empregadas domésticas, em suas casas, consigam água, mas carregada por maiores e menores distâncias ou disponham de água próxima extraída de algum poço, mas não daquela tratada, sujeitando suas crianças a doenças e, mesmo, morte por diarreia. Podem ter geladeira, mas com poucos alimentos ou, mesmo, vazia deles, conforme o período do mês. Podem ter fogão e ferro elétrico, mas são obrigadas a recorrer ao uso de fogareiro a querosene e/ou ao ferro a carvão, por falta de dinheiro para o gás e a energia elétrica, essa que, em geral, acessada por meio de "gatos", não assegura condições de funcionamento adequado dos aparelhos domésticos.

Há padrões tecnológicos diversos no espaço territorial brasileiro. Nem sempre a mesma tecnologia pode chegar a diferentes lugares do país. No Rio de Janeiro, em meados dos anos 1940, Candelária, tia de minha mãe, casada com um almirante de importante família carioca, moradora de um belo sobrado em Botafogo, com dois jovens filhos, já dispunha de geladeira e fogão elétricos importados. Para minha avó, sua irmã, casada com oficial de Marinha de menor graduação, moradora de uma casa de vila no subúrbio de Todos os Santos dessa mesma cidade, isso era bem diferente. Modista, ela costurava para fora e para a casa. Administrava rigidamente a totalidade dos ganhos familiares, cobrindo ajuda com quatro filhos adultos e solteiros em casa, e de fora dela, com os quatro casados e seus muitos netos. A energia elétrica, tão cara, era poupada e por isso, tinha como geladeira um pequeno móvel de madeira, fechado com travas que recebia uma grande pedra de gelo, transportada por bicicleta; embrulhada em jornal; ela podia conservar alguns alimentos por algum tempo. Já na casa de meus pais, em Três Lagoas (hoje MS) na mesma época, embora houvesse renda para um dado padrão médio de conforto, não havia gelo, nem geladeira, nem mesmo essa de minha avó. Ao entardecer, a luz só era ligada por poucas horas; à noite, acendiam-se velas. De gelo, circulava pelas ruas um vendedor de picolé de groselha, açucarado que, chupado, ficava branco. As conservas seguiam práticas do século XIX, guardadas na despensa, um lugar de mistérios e de interdições para crianças como eu.

A tecnologia, além de variar conforme as circunstâncias de um mesmo tempo e espaço, serve a ganhos e a perdas. Ela em si não traz conforto para todos, mesmo quando reduz a intensidade das tarefas domésticas de outrora. É próprio dos séculos XX e XXI o sentimento de que a energia humana feminina, economizada 
em diferentes tarefas, produza uma incessante reprogramação de tempo aplicado a novas tarefas. Ganhos com economias de tempo têm ampliado a intensidade de ocupações e jornadas de trabalho de mulheres e, também, de homens, com e sem ganhos monetários e sociais a mais. O mundo doméstico é o grande mercado consumidor de produtos industriais para todos os fins. Acionar esse consumo por meio de crédito faz o crônico endividamento de famílias, de muitas penalizações, favorecendo, como nunca, o sistema bancário e o industrial. Hoje a tecnologia digital, em especial, vem transferindo encargos de escritórios para as residências, ocupando - intensivamente homens e mulheres e com redução de custo para seus empregadores. A intensidade de ocupação do tempo em diferentes atividades é muito maior que no passado. Vale lembrar que o capitalismo ainda é aquele (Castro, 1979). Conhecer significados desse tempo de acelerações é um problema civilizador desses séculos, matéria de muitas reflexões contemporâneas sobre a felicidade humana. O que esses ritmos acelerados estão produzindo em nossas vidas e nas vidas domésticas de hoje?

Há por considerar ainda uma singular resistência ao uso de tecnologia ou sua lenta incorporação por parte de algumas mulheres, por razões muitas, entre elas, por reduzir a visibilidade de feitos domésticos, lembrando seu valor simbólico. Lembro a personagem Alice de José de Alencar, em O tronco do Ipê, em cena de meados do século XIX, ainda prefere fazer suas rendas, em vez de comprar as de fabricação inglesa disponíveis no mercado: ela exibe suas prendas, valorizando seu trabalho e a si mesma como moça casadoira (Costa, 2000). Há casas que mantêm fogão à lenha ao lado do elétrico ou à gás, modo de preservar memórias culinárias do passado.

\section{Conclusão}

Há cautelas a tomar nos estudos do emprego doméstico: análises conjunturais e trato aligeirado de dados quantitativos muito ocultam desse trabalho no Brasil. Em larga monta, ele é negociado e contratado fora das regras de emprego. Hoje, a produção do conforto e a proteção social oferecidos pelo emprego doméstico é a tarefa que mais ocupa as mulheres brasileiras, tantas delas, mulheres chefes de família.

Os ganhos desse emprego crescentes nas grandes cidades, onde também os salários de segmentos médios se elevam, só são conhecidos nos registros oficiais sobre a população ocupada. A estimativa de empregados(as) domésticos(as) é de 
7,2 milhões de pessoas, tem deixado de considerar a demanda em espiral por esse trabalho. Isso exige novas referências de análise. O trabalho doméstico se transforma, mas também inventa tradições; hoje, no caso francês, muitas mulheres de camadas médias se autorizam a cuidar de suas casas e de seus filhos; para uns/ umas essa é uma escolha sensata, para outros(as) não (Badinter, 2010). Mulheres brasileiras aplicam-se ao mundo da casa mais horas que os homens. O trabalho masculino, em alguns casos, hoje, parece estar mais próximo das tarefas domésticas, daí impor-se o exame de complementaridades masculinas e femininas. Nos séculos XX e XXI, o exame do emprego e o trabalho doméstico. sob muitas invisibilidades, exige, ainda referências sobre seus sinais políticos e seus significados para os nossos rumos civilizadores.

Recebido em: 14/7/2014 - Aprovado em: 4/8/2014

\section{Fontes documentais}

ARQUIVO NACIONAL. Inventiva brasileira 1870-1910. Exposição de documentos do acervo de privilégios industriais do Arquivo Nacional. Rio de Janeiro: Espaço Cultural BNDES, set. 1994.

SERVIÇO DOMÉSTICO. Propostas de Antonio Felix Garcia de Infante. Josino da Silva, Jeronymo de Assis Pinto Freitas\&/C.1884, Códice 48-4-56, AGCRJ, p. 4647.

\section{Referências bibliográficas}

ASSIS, Machado de. Diário do Rio de Janeiro (1864-1867). In: ASSIS, Machado de. Crônicas (1864-1867). Rio de Janeiro: W. M. Jackson, 1938. p. 282 e 283.

BADINTER, J. Le conflit: la femme e la mère. Paris: Éditions Flammarion, 2010.

BERNARDES, M. T. Crescenti. Mulheres de ontem? Rio de Janeiro-século XIX. São Paulo: T. A. Queiroz Editor, 1989. p. 155.

BERNARDINO-COSTA, Joaze. Sindicatos das trabalhadoras domésticas no Brasil. Teorias da descolonização e saberes subalternos. Tese (Doutorado em Sociologia) - Departamento de Sociologia, Universidade de Brasília, Brasília, 2007. 
BORIN, Françoise. Uma pausa para a imagem. In: DUBY, G.; PERROT, M. História das mulheres no Ocidente: do renascimento à Idade Moderna. Tradução de Alda Maria Durães et al. Porto: Edições Afrontamento/São Paulo: Ebradil, 1994. p. 253-293.

BRASIL. Instituto Brasileiro de Geografia e Estatística (IBGE). Pesquisa Mensal de Emprego (PME). Algumas das principais características dos trabalhadores domésticos vis-à-vis a população ocupada. Brasília, fev. 2010.

CASTEL, R. Metamorfoses da questão social: a crônica do salário. Tradução I. D. Poleti. Petrópolis: Vozes, 1998.

CASTRO, A. B. de. O capitalismo ainda é aquele. Rio de Janeiro: Forense Universitária, 1979.

CORALINA, Cora. Poemas dos becos de Goiás e estórias mais. 20. ed. São Paulo: Global, 2001.

COSTA, S. G. Metáforas do tempo e do espaço doméstico. (Rio de Janeiro, século XIX). Tese de doutorado em História. Universidade Federal Fluminense, Niterói, 1996.

. Pau-para-toda-a-obra. A matriz de subordinação da mão de obra antes do sistema fabril Brasil: século XVI a XIX. Dissertação (Mestrado em História) — Universidade Federal Fluminense, Niterói, 1988.

. Alice por Alice (autoimagem e amarras femininas em $O$ tronco do ipê). Tempo/

Universidade Federal Fluminense, Departamento de História, Rio de Janeiro, 7 Letras, v. 5, n. 9, p. 29-42, jul. 2000.

. Das desventuras de ser doutora. Caderno Espaço feminino, n. 12, v. 15, p. 103-114, 2004. Uberlândia, 2005.

. Diário de umas e outras meninas: práticas domésticas e educação. Diamantina, Minas Gerais, fins do século XIX. In: LOBO, Y.; FARIA, L. (Orgs.). Vozes femininas do Império e da República. Rio de Janeiro: Quartet/Faperj, 2008. p. 47-77.

DARWIN, C. Viagem de um naturalista ao redor do mundo (trechos escolhidos). Tradução J. Carvalho. São Paulo: Companhia Brasil Editora, 1979. p. 9.

EBEL, E. O Rio de Janeiro e seus arredores em 1824. Tradução J. de S. Leão Filho. São Paulo: Editora Nacional, 1972. p. 25-30.

FOUCAULT, M. Nascimento da biopolítica. Curso no Collège de France (1978-1979). Edição estabelecida por M. Senellart sob direção de F. Ewald e A. Fontana. Tradução E. Brandão, revisão de tradução C. Berliner. São Paulo: Martins Fontes, 2008.

FREIRE, M. Martha de L. Mulheres mães e médicos. Rio de Janeiro: FVG, 2009. 
FREIRE, Maria Martha de Luna. Mães, mulheres e médicos. Discurso maternalista no Brasil. Rio de Janeiro: Fundação FGV, 2009.

GRAHAM, Maria Diário de uma viagem ao Brasil. Tradução A. J. L. Belo Horizonte: Itatiaia; São Paulo: Ed. da Universidade de São Paulo, 1990. p. 136.

HUFFINGTON, Arianna. Third World America. Nova York: Broadway Books, 2011.

LANGONI, C. G. Distribuição de renda e desenvolvimento econômico no Brasil. Rio de Janeiro: Expressão e Cultura, 1973.

LUCCOCK. J. Notas sobre o Rio de Janeiro e partes meridionais do Brasil. Tradução Milton da S. Rodrigues, apresentação de M. G. Ferri. Belo Horizonte: Itatiaia; São Paulo: Ed. da Universidade de São Paulo, 1975, p. 76-77.

MARX, K. O capital. 3. ed. Rio de Janeiro: Civilização Brasileira, 1975. Livro 1, v. 1, p. 455.

MAURO, Frédéric. Origens da desigualdade entre os povos da América. Tradução Carlos Nelson Coutinho. São Paulo: Brasiliense, 1986. p. 98.

MORLEY, H. Minha vida de menina. Cadernos de uma menina provinciana nos fins do século XIX. 18. ed. Rio de Janeiro: José Olympio, 1997.

PASSOS, Rachel Gouveia. As vozes que ecoam: mulheres, ressentimentos e saúde mental. Cadernos de História da Ciência, São Paulo, Instituto Butantã, v. 6, n. 1, p. 129-140, jun./ jul. 2010.

PINTO, Camila F. Redes sociais informais e integralidade nas politicas públicas. Trabalho de Conclusão de Curso, Departamento de Serviço Social de Niterói. Universidade Federal Fluminense, Niterói, 2007.

REBOREDO, F.; PAIS, J. A construção naval e a destruição do coberto florestal em Portugal: do século XII ao século XX. Ecologi@, n. 4, jan./abr. 2012. Disponível em: <http://speco. fc.ul.pt/revistaecologia.html>. Acesso em: 21 dez. 2012.

REGAR, Silvia. Sinal dos tempos. Revista $O$ Globo, Rio de Janeiro, ano 1, n. 358, 5 jul. 2011, p. 30-34.

RYBCZYNSKI, W. Le confort: six siècles d'habitation. Tradução do inglês por Claire Dupond. Montréal: Èditions du Roseau, 1989. p. 9-10.

SAFFIOTI, H. Emprego doméstico e capitalismo. Petrópolis: Vozes, 1978.

SAHLINS, M. Ilhas de história. Rio de Janeiro: Zahar, 1990.

SOIHET, R. O feminismo tático de Bertha Luz. Florianópolis: Editora Mulheres, 2006. 